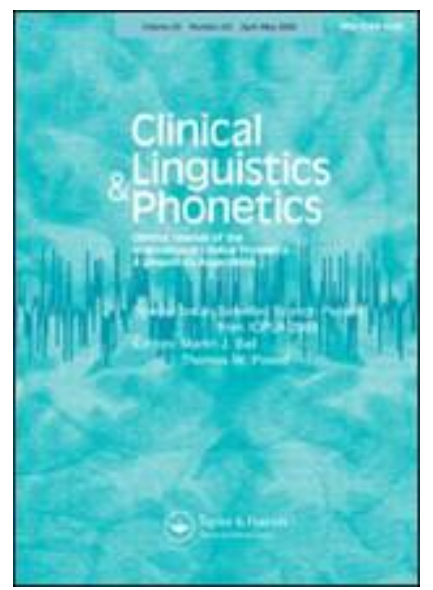

\title{
Voice Onset Time and Formant Frequencies in Arabic Stuttered Speech
}

\begin{tabular}{|r|l|}
\hline Journal: & Clinical Linguistics \& Phonetics \\
\hline Manuscript ID & TCLP-2020-0018.R2 \\
\hline Manuscript Type: & Original paper \\
\hline Keywords: & VOT, F2, Arabic, stuttering < speech disorders \\
\hline \multicolumn{2}{l}{} \\
\end{tabular}

\section{SCHOLARONE Manuscripts}




\title{
Voice Onset Time and Formant Frequencies in Arabic Stuttered Speech
}

\author{
Feda Al-Tamimi ${ }^{1}$ and Peter Howell ${ }^{2}$ \\ 1 Jordan University of Sciences and Technology, Irbid, Jordan; 2 University College London, \\ England
}

\begin{abstract}
Contact details: Postal Address of corresponding author: Department of Rehabilitation Sciences, Applied Medical Sciences Faculty, Jordan University of Sciences and Technology, Irbid, Jordan (-tamimi@just.edu.jo) Mobile No. +962799339927; Fax: +962 27201000
\end{abstract}

Running Title: VOT and Formant Frequencies in Stuttered Speech 


\begin{abstract}
Neuromuscular models of stuttering consider that making transitions between phones results in inappropriate temporal arrangements of articulators in people who stutter (PWS). Using this framework, the current study examined the acoustic productions of two fine-grained phonetic features: voice onset time (VOT) and second formant (F2). The hypotheses were that PWS should differ from fluent persons (FP) in VOT duration and F2 onset frequency as a result of the transition deficit for environments with complex phonetic features such as Arabic emphatics. Ten adolescent PWS and 10 adolescent FPs participated in the study. They read and memorized four monosyllabic plain-emphatic words silently. Data were analyzed by Repeated Measures ANOVAs. The positive and negative VOT durations of $/ \mathrm{t} / \mathrm{vs} . / \mathrm{t}^{\mathrm{s}} /$ and $/ \mathrm{d} / \mathrm{vs} . / \mathrm{d}^{\mathrm{s}} /$ and F2 onset frequency were measured acoustically. Results showed that stuttering was significantly affected by emphatic consonants. PWS had atypical VOT durations and F2 values. Findings are consistent with the atypicality of VOT and F2 reported for English-speaking PWS. This atypicality is realized differently in Arabic depending on the articulatory complexity and cognitive load of the sound.
\end{abstract}

Keywords: VOT, F2, Arabic, Stuttering 


\section{Introduction}

Fluent speech requires precisely timed coordination at the neurocognitive and muscular levels. Any disruption to coordination can result in stuttering (Ludlow \& Loucks, 2003; Walsh \& Smith, 2013). A number of neuro-physiological (De Nil, 1999), neuromuscular (Van Riper, 1990) and multifactorial (Howell \& Rusbridge, 2011; Smith, 1999) models have been proposed to explain why stuttering occurs. These models suggest different anatomical, physiological, neuropsychological, linguistic, emotional and cognitive determinants of stuttering events. At the linguistic level, early work (Brown, 1937, 1938a, 1938b, 1945; Johnson \& Brown, 1935; Brown \& Moren, 1942) suggested that stuttering events are more likely to occur on words that carry certain factors including grammatical type, word length, sentence position and word-initial phoneme, due to the linguistic complexity associated with them.

Later studies have provided empirical evidence for a relationship between speech complexity and stuttering. The focus has mainly been on identifying what factors determine stuttering loci. Factors include phonetic and phonological aspects of words (e.g. type of initial consonant, presence of a consonant cluster and occurrence of early vs. late acquired consonants; Throneburg, Yairi, \& Paden, 1994), morphological properties (e.g. word length; Marshall, 2005) and prosodic features (e.g. stress; Wingate, 2002), etc. Schemes are available for measuring these and other features of words (Throneburg et al., 1994; Jakielski, 1998) that provide objective weightings of word complexity. The research on these linguistic dimensions shows that stuttering increases as speech item complexity increases (Buhr \& Zebrowski, 2009; Howell, Au-Yeung, \& Sackin, 2000; Howell, Au-Yeung, Yaruss, \& Eldridge, 2006; MacPherson \& Smith, 2013).

Since speech is the acoustic result of a motor action patterned continuously over time (Van Riper, 1982), its component segments require precisely controlled laryngeal activities that are 
coordinated with smooth transitions of the articulators (MacNeilage \& Davis, 2000). PWS have variously been characterized as having: deficits making articulatory movements between phones (Wingate, 1969); inappropriately-timed coarticulation (Van Riper, 1982); unstable timing programs (Cooper \& Allen, 1977); impaired laryngeal gestures (Conture, Schwartz, \& Brewer, 1985); and temporally-, and spatially-restricted articulatory adjustments (Klich \& May, 1982). Smith, Goffman, Sasisekaran, \& Weber-Fox (2012:345) state that in stuttering events 'the flow of fluent speech is disrupted as the nervous system fails to generate the appropriate command signals to drive the muscles involved in speech production.' This atypical coordination is not restricted to their speech events; PWS show atypical coordination of speech motor skills in fluent speech as well (Caruso, Abbs, \& Gracco, 1988; McClean, Kroll, \& Loftus, 1990; McClean, 2004). On the other hand, a number of reports have examined acoustic and articulatory transitions between phones and found no difference between PWS and FP (Frisch, Maxfield \& Belmont, 2016; Didirkova \& Hirsch, 2019, Smith, Sadagopan, Walsh, \& Weber-Fox, 2010; Sussman, Byrd, \& Guitar, 2011). Findings showing differences in patterns of coarticulation between PWS and FS have been interpreted as showing that fluent and disfluent episodes in the speech of PWS are positioned along a continuum of speech motor coordination rather than being a dichotomous phenomenon (Usler, Smith, \& Weber, 2017). PWS also show lower speed rate and longer movement durations in nonspeech tasks (Loucks \& De Nil, 2006). These findings have been substantiated by neuroimaging studies that show that the brain activation levels of PWS differ from those of FPs in speech and nonspeech motor tasks (Chang, Horwitz, Ostuni, Reynolds, \& Ludlow, 2011). Usler, Smith, \& Weber (2017) interpret these neuroimaging findings as further confirmation that deficits underlying stuttering are sensorimotor. Studies that have examined the relation between the level of complexity of speech items and stuttering have usually reported an 
increase in stuttering as speech item complexity increases. For instance, in their study on the influence of length and syntactic complexity on the speech motor stability of PWS, Kleinow \& Smith (2000) reported a decrease in speech motor stability of PWS when the stimuli were complex. Howell et al. (2000) focused on the effect of phonologically complexity using Throneburg et al.'s (1994) late-emerging consonants, consonant cluster and word length scheme. The results showed that stuttering was higher on the phonologically complex sounds.

The majority of stuttering research is based on English-speaking PWS. Studies on linguistic complexity and stuttering in Arabic are particularly rare. Abdalla, Robb, \& Al-Shatti, (2010) examined the content-function word dichotomy and their frequency of occurrence in stuttered speech of Arabic PWS. Results showed no significant differences in the amount of stuttering on function or content words but that a significant amount of disfluency occurred on the combined content-function words that Arabic grammar is unique for. This type of word has greater linguistic and motor requirements compared to content or function words (Abdalla et al., 2010). Hence, content-function words have high planning and execution demands. Al-Tamimi, Khamaiseh, \& Howell (2013) investigated the relationship between stuttering rate and word category. The researchers developed an Arabic Index of Phonetic Complexity (AIPC) based on a number of complex phonetic features following work by Jakielski (1998) on English. PWS were more likely to stutter on words that had high AIPC score.

The current study examined the acoustic productions of two fine-grained phonetic features, voice onset time (VOT) and second formant (F2) onset frequency, of emphatic consonants. The approach is based on the neuromuscular model that views stuttering as a result of transition deficit and inappropriate temporal arrangements of complex motor skills. The hypothesis tested in the present study is that PWS differ from fluent persons (FP) in VOT duration and F2 onset. These 
differences are considered to result from transition deficits that arise in environments with complex phonetic features. Arabic emphatic sounds require high levels of muscular activity in laryngeal, pulmonary and articulatory systems. VOT and F2 are phonetic features that need to be precisely timed and result from coordinated laryngeal activity with rapid transition movements of the articulators. The simultaneous muscular activities accompanied by precisely timed transitions are expected to induce more chance of stuttering events and to produce acoustic outputs that differ from those of FP. The significance of the present work is that it is the first study which examines VOT and F2, as fine-grained phonetic features, in the production of emphatic sounds by PWS in Arabic. It adds more evidence to the neuromuscular model that views atypical speech as a deficit in coarticulation. This research potentially may contribute to additional explanations of stuttering and, in turn, improved therapy practices. In addition, it is the first study that compares results on Arabic and English-speaking PWS.

\section{Acoustic Features and Stuttering}

Speech acoustics of PWS has been widely investigated. Many researchers have focused on the temporal (VOT, vowel duration, consonant closure time, etc.) and spectral (formant frequencies) aspects of stuttered events (Zebrowski, Conture, \& Cudahy, 1985; Howell \& Williams, 1992; Robb \& Blomgren, 1997; Howell \& Vause, 1986; Yaruss \& Conture, 1993; Bauerly \& Paxton, 2017; Bauerly, 2018; Bauerly, Jones, \& Miller, 2019). Acoustic analysis can determine the laryngeal and supralaryngeal articulatory behavior of PWS. Voice Onset Time (VOT) and second formant (F2) onset in the environment of emphatic consonants are the focus of the current study and the way they are realized by PWS is investigated. The current section documents the complexity of VOT, F2 and emphatics for PWS. This complexity fits within the restricted motor skills of PWS. 
Specifically it shows that VOT precise timing, F2 onset and emphatics complex articulation are challenging for PWS to maintain.

\section{VOT as a Temporal Parameter}

Voice onset time is an acoustic temporal parameter that differentiates between syllable-initial voiceless and voiced plosives in languages. It is the interval between closure release and vocal fold excitation. It provides 'an inferential estimate of speech motor control, requiring fine motor coordination of the respiratory, phonatory and articulatory structures' (Robb, Gilbert, \& Lerman, 2005: 125). From a physiological and aerodynamic viewpoint, VOT arises via fine motor coordination building on the adduction and abduction of laryngeal muscles and airflow. The posterior cricoarytenoid and interarytenoid muscles (Hirose, Yoshioka, \& Niimi, 1978) are responsible for these laryngeal muscles actions. Languages differ on the VOT contrast they manifest. Contrasts include; two-way contrast, voiced vs. voiceless (e.g. English, Arabic); threeway contrast, voiced, voiceless unaspirated and voiceless aspirated (e.g. Thai) and four-way contrast, voiced, voiceless unaspirated, voiceless aspirated and voiced aspirated (e.g. Hindi) (Abramson \& Whalen, 2017).

In Arabic, voiceless unaspirated plosives have zero or short lag VOT with a 0-30 ms range of duration; while, voiced plosives have negative lead VOT reaching up to approximately -120 ms (Al-Tamimi, Tarawneh \& Howell, submitted). Lead or negative VOT occurs when vocal fold vibration precedes the plosive release. Lag or positive VOT occurs when there is a delay in vocal fold vibration after the release of the plosive. When compared to lag VOT, lead VOT requires additional laryngeal and pharyngeal adjustments (Keweley-Port \& Preston, 1974). The acoustic information of lead VOT is less salient than lag VOT (Aslin, Pisoni, Henness, \& Perey, 1981; Deuchar \& Clark, 1996) Lead VOT is acquired late (around age five) by children; this indicates 
its articulatory difficulty (Allen, 1985). Short lag VOT is achieved by opening the glottis at any time during oral gestures and is usually mastered before age one (Kong, 2009). At the perception level, adults discriminate between sounds that exceed $-20 \mathrm{~ms}$ and $+20 \mathrm{~ms}$ durations. Rosen \& Howell (1987) report that humans can perceive the temporal order of two sound events with asynchronies greater than about $20 \mathrm{~ms}$. Onsets less than $20 \mathrm{~ms}$ are perceived by humans as simultaneous and are difficult to judge temporally (Hay, 2005). In Arabic, the lead region for voiced sounds exceeds the $-80 \mathrm{~ms}$, threshold, while the lag region for voiceless stops is below +20 ms. threshold (Al-Tamimi et al., submitted).

VOT production involves control and coordination of laryngeal and multiple oral motor movements involving the sublaryngeal, laryngeal, and supralaryngeal systems. The basic element in this control is the coordination of precise subtle timing of the laryngeal maneuvers and oral release. Lack of coordination and imprecise timing might arise for a number of linguistic, cognitive, emotional, behavioral, aerodynamic, articulatory and neurophysiological reasons (Cho $\&$ Ladefoged, 1999). For these reasons, studies have focused on VOT as a possibly complex factor inciting stuttering (Healey \& Gutkin, 1984; Jäncke, 1994; Max \& Gracco, 2005; Arenas, Zebrowski, \& Moon, 2012). These studies have revealed distinctive voicing patterns, more specifically, longer VOTs in the speech of PWS when compared to those of fluent persons (FP) (Healey \& Gutkin, 1984; Rezaei-Aghbash, Whiteside, \& Cudd, 2000; Max \& Gracco, 2005; Hillman \& Gilbert, 1977; Zimmermann, 1980). These longer VOT values might be due to the lack of coordination and reciprocity between cricothyroid and cricoarytenoid muscles responsible for vocal folds abduction and adduction during stuttering (Shapiro, 1980). In certain cases, studies have found longer VOT for voiced rather than voiceless plosives (Healey \& Gutkin, 1984) or no significant differences in VOT between PWS and FP speech (Zebrowski, Conture, \& Cudahy, 
1985; Borden, Baer, \& Kenney, 1985). These studies investigated VOT in the speech of PWS in languages following the short lag and long lag contrast. Children acquire this voicing contrast at around the age of 2;0. Lag vs. lead VOT contrast is acquired late (after age 5;0) due to the fact it involves additional laryngeal and supralaryngeal adjustments.

All Arabic dialects have the late acquired long lead VOT (Khattab, 2000). Its late acquisition is due to the difficulties in realizing the laryngeal control and precise subtle timing. Its acquisition coincides with the inception of stuttering. Accordingly, its examination in the speech of PWS fits well within the frame of timing and coarticulatory deficits of PWS. Based on the coarticluation difficulty they may suffer from, PWS would be expected to produce VOT duration different from those of FP. English-speaking PWS studies show that PWS produce longer VOT durations than FP. Arabic (short lag vs. long lead) differs from English (short lag vs. long lag) with regard to VOT direction and duration. Given these differences, a comparison of Arabic with Englishspeaking PWS is desirable.

\section{Formant Frequency as a Spectral Parameter}

Since speech is characterized by spatial and temporal organization of movements within a phenomenon known as coarticulation, or more precisely phoneme sequencing (Howell, 1996; Howell \& Harvey, 1983) different studies have proposed that stuttering is a disorder of speech motor discoordination (Wingate, 1969, Howell \& Vause, 1986; Klich \& May, 1982; Hawkins, Walden, Montgomery, \& Prosek, 1987; Yaruss \& Conture, 1993). Despite the different methods and analysis strategies adopted in these studies, researchers, in general, agree 'that the lingual coarticulation accompanying a disfluency differs from the coarticulation that characterizes normal fluency' (Robb \& Blomgren, 1997, P. 2). Due to this sound-to-sound transitioning difficulty, the transitions at consonant-vowel boundaries are affected. Researchers have examined F2 transition 
as an acoustic spatial feature representing the anterior and posterior movement of the tongue during speech. F2 duration, direction, slope and rate appeared to be irregular, limited or faster in the fluent and stuttered events of PWS (Howell \& Vause, 1986; Howell, Williams, \& Vause, 1987; Klich \& May, 1982; Robb \& Blomgren, 1997; Dehqan, Yadegari, Blomgren, \& Scherer, 2016).

In normative Arabic studies, F2 is lowered in the environment of emphatic sounds due to the simultaneous alveodental and oropharyngeal configuration accompanying the production of these sounds. This complex articulatory configuration might be difficult for PWS to achieve; accordingly, their F2 would be irregular.

\section{Emphatics in Arabic}

Arabic emphatics are the voiceless alveolar plosive $/ t^{\mathrm{t}} /$, voiced alveolar plosive $/ \mathrm{d}^{\mathrm{\varsigma}} /$, voiced interdental fricative $/ \delta^{\varsigma} /$ and voiceless alveolar fricative $/ s^{\varsigma} \%$ Their plain, i.e. non-emphatic counterparts are: /t/,/d/,/ठ/ and/s/, respectively. Emphatics are articulatorily complex sounds; they are among the late consonants acquired by children (Amayreh, 2003). They are produced through rapid complex articulatory movements (Odisho, 1973) with simultaneous primary and secondary constrictions; the primary constriction is in the alveodental region and the secondary constriction is achieved through tongue root retraction into the oropharynx. In their videofluoroscopic and nasoendoscopic study, Al-Tamimi, Alzoubi, \& Tarawneh (2009) reported greater tension on the tongue body, retraction of tongue root into the oropharynx and hyoid bone elevation and larynx raising in the production of emphatic sounds.

These physiological configurations require simultaneous, successive and rapid motor movements. Any disruption in these movements could lead to stuttering (Van Riper, 1982). One of the reasons for this disruption might be the intrinsic articulatory complexity of the sound. The 
late acquisition of these sounds coincides with the age of modal inception of stuttering. They therefore have earlier impact on stuttering (Yairi \& Ambrose, 2005).

Normative Arabic studies show that emphatics differ from their plain counterparts temporally and spectrally. The emphatic stops $/ \mathrm{t}^{\mathrm{t}} /$ and $/ \mathrm{d}^{\mathrm{\varsigma}} /$ have VOT values shorter than their plain counterparts /t/ and /d/ in different Arabic dialects (Yeni-Komshian, Caramazza, \& Preston, 1977; Al-Ani, 1970; Zeroual, Hoole, Fuchs, \& Esling, 2007). In addition, emphatic consonants have lower F2 in the onset of the following vowel compared to their plain counterparts. In all Arabic dialects, F2 lowering of the vowel following the emphatic consonants has mainly been the consistent feature of emphasis (Jongman, Herd, \& 1-Masri, 2007; Watson, 2007; Zawaydeh, 1999; Al-Tamimi \& Heselwood 2011).

The main aim of the current study was to examine the role of articulatory complex emphatic sounds with fine-grained phonetic features in stuttering events. The articulatory complexity of emphatics increases as VOT and F2 require rapid coarticulatory movements to achieve the oral configuration and smooth transition of articulators in a timely manner. PWS need to make simultaneous primary and secondary oral constrictions in the alveodental and oropharyngeal regions with timing coordination between the oral and phonatory systems to produce fine-grained phonetic features in the vicinity of emphatic consonants. This complex articulatory environment fits within the general opinion that stuttering is the result of atypical coordination of speech motor skills needed to produce sounds with high propositional values. The current study hypothesizes that PWS will show VOT durations and F2 values different from what normative data reveal. 


\section{Methodology}

\section{Sample}

Ten adolescent male participants ranging in age from $11 ; 0$ to $14 ; 0$ (mean age $12 ; 3$ ) participated in the study. They were independently diagnosed by certified Jordanian speech language therapists based on a Jordanian version of Stuttering Severity Instrument for children and adults (SSI-3) (Riley, 1994). This version was used in a previous study on stuttering and anxiety in Jordanian children (Roud, 2011). None of the participants had received formal stuttering therapy at the time of speech sample collection. They or their guardians signed written informed consent to participate in the study. Data collection started in December 2017. All participants were native Jordanian Arabic speakers with normal hearing; no participant had voice, articulation or phonological disorders. They were diagnosed with severe stuttering as they had a minimum of $20 \%$ stuttering events (repetition, prolongation, and blockage) out of the total number of tokens each produced. They read silently and memorized four monosyllabic plain-emphatic words, /taab/ (repented) vs. / $t^{\uparrow} \mathrm{aab} /$ (recovered); /daar/ (house) vs. / $\mathrm{d}^{\complement} \mathrm{aar} /$ (harmful), written on a sheet of paper. Participants were then asked to retrieve the words and produce each of them three times (e.g./tab/, /tab/, /tab/) using their habitual loudness level and typical speaking rate with short pauses between words. The technique used in the current study was similar to the technique used in previous studies (Dehqan, Yadegari, Blomgren, \& Scherer, 2016; Robb \& Blomgren, 1998). Perceptually fluent productions of words were required for analysis. A control group (FP) consisting of 10 adolescent male participants (mean age 13;0) produced each of the target words three times in the same way that PWS did. Other researchers used reading procedures to elicit data similar to the current study data (Llewellyn, 1994; Viswanath, Nagalapura, Rosenfield, \& David, 2000). 


\section{Reliability and Statistical Analysis}

In total, 240 tokens ( 4 plosives*3 repetitions*20 participants) were measured. As an estimate of inter-rater reliability, a random sample consisting of $10 \%$ of the data was remeasured independently by a trained phonetician. A Pearson-Product Moment correlation analysis showed a significant correlation coefficient $(\mathrm{r}=.913, \mathrm{p}=.001)$ indicating a high test-retest reliability.

Means of VOT durations and F2 values of the three repetitions of every monosyllabic plainemphatic word were calculated and included as dependent variables in repeated-measures ANOVAs and Bonferroni post hoc test. Bonferroni post hoc test differences in means (MD) were used to show whether or not the effect of stuttering on VOT and F2 was significant. To know the magnitude of stuttering on VOT and F2, effect sizes (Partial eta squared, $\eta p^{2}$ ) were also reported. In statistics, effect size ranges from trivial $(<60 \%)$ to large $(>80 \%)$ (Cook, 2008).

\section{Acoustic Analysis}

The positive and negative VOT durations of $/ \mathrm{t} / \mathrm{vs}$. $/ \mathrm{t}^{\S} /$ and $/ \mathrm{d} / \mathrm{vs}$. / $\mathrm{d}^{\S} /$ and F2 frequency were measured by a trained phonetician. Lead VOT for $/ \mathrm{d} /$ and $/ \mathrm{d}^{\mathrm{f}} /$ was measured from the onset of glottal pulse to the plosive burst, while lag VOT for $/ t /$ and $/ t^{t} /$ was measured from the onset of the plosive burst to the first visible glottal pulse. F2 onset was measured at the onset of the first glottal pulse following the plosive.

\section{Results}

Results (Table 1) revealed that PWS VOT $(\mathrm{F}=1158.07 ; \mathrm{df}=1.93 ; \mathrm{P}=0.00)$ durations and $\mathrm{F} 2$ onset values $(\mathrm{F}=101.26 ; \mathrm{df}=3.00 ; \mathrm{P}=0.00)$ differed significantly from those of FP. PWS produced significantly $\left(\mathrm{MD}=-19.63^{*}\right)$ longer $/ \mathrm{d}^{\varsigma} /$ VOT $(299.22 \mathrm{~ms})$ than $/ \mathrm{d} / \mathrm{VOT}(202.78 \mathrm{~ms})$, while FP produced significantly $(\mathrm{MD}=12.33 *)$ shorter $/ \mathrm{d}^{\mathrm{s}} / \mathrm{VOT}(61.33 \mathrm{~ms})$ than $/ \mathrm{d} / \mathrm{VOT}(121.89 \mathrm{~ms})$. On 
the other hand, PWS $\left(\mathrm{MD}=3.18^{*}\right)$ and FP $\left(\mathrm{MD}=6.68^{*}\right)$ had $/ \mathrm{t} /$ short lag VOT significantly longer than that of $/ t^{\natural} /$. However, PWS $/ t /$ and $/ t^{\natural} /$ VOT durations were significantly shorter than $\mathrm{FP} / \mathrm{t} /$ and $/ t^{\natural} /$ VOT durations. There was no significant difference between FP emphatic $/ t^{\natural} /$ VOT and PWS plain /t/ VOT In normative data, the emphatic plosive VOT is shorter than its plain counterpart. In the current study, PWS emphatic long lead was longer than its plain counterpart. In addition to that, PWS plain short lag VOT duration was similar to FP emphatic short lag VOT duration.

As for F2, results revealed significant differences between PWS and FP with regard to the emphatic plosives. FP lowered F2 in the vicinity of the emphatic voiceless and voiced plosives. The differences in $\mathrm{F} 2$ means between $\mathrm{FP} / \mathrm{t} / \mathrm{vs} . / \mathrm{t}^{\mathrm{c}} /\left(\mathrm{MD}=37.38^{*}\right)$ and $/ \mathrm{d} / \mathrm{vs} . / \mathrm{d}^{\mathrm{c} /}\left(\mathrm{MD}=12.03^{*}\right)$ plosives were statistically significant. PWS F2 was significantly $\left(\mathrm{MD}=19.72^{*}\right)$ lower in the vicinity of the emphatic voiceless plosive $/ t^{\mathrm{t}} /$ only. PWS and FP did not differ significantly (MD $\left.=0.49\right)$ with regard to /t/ F2; FP had their /t $₹ /$ F2 significantly $(\mathrm{MD}=-16.81 *)$ lower than $\mathrm{PWS} / \mathrm{t}^{\natural} / \mathrm{F} 2$. As for the voiced plosives, PWS had /d'/ F2 (1266.00 Hz) atypically higher than /d/ F2 $(1136.56 \mathrm{~Hz})$.

\section{Insert Table 1 Here}

Results showed that stuttering had a large effect on VOT $\left(\eta p^{2}=0.9954\right)$ and F2 onsets $\left(\eta p^{2}=\right.$ 0.9702) of all sounds.

Generally speaking, PWS productions are in line with the atypical VOT durations and F2 values reported in English-speaking stuttering studies (Robb \& Blomgren, 1997; Max \& Gracco, 2005). In comparison with FP, PWS have atypical VOT durations and F2 values. Their emphatic long lead VOT is atypically longer than their plain long lead VOT. Their plain short lag VOT duration matches FP emphatic short lag VOT duration. As for F2, PWS atypically have the emphatic voiced /d $/$ F2 onset higher than their plain /d/ F2 onset. Although there are no significant differences between PWS and FP/t/ F2, FP have /t $/$ F2 significantly lower than PWS / $\mathrm{t}^{\mathrm{t}} / \mathrm{F} 2$. 


\section{Discussion}

The main objective of the current study was to investigate the role of phonetically complex sounds in stuttering; two acoustic features were examined: VOT duration and F2 onset value. The hypothesis tested in the present study was that PWS should differ from FP in VOT duration and F2 onset as a result of transition deficit in the environment of complex phonetic features. Results revealed that emphatic sounds played a significant role in the atypical speech of PWS. Mean VOT durations of $/ \mathrm{d} /$ and $/ \mathrm{d}^{\mathrm{c}} /$ were significantly longer in the productions of PWS than in the productions of FP. PWS produced longer $/ \mathrm{d}^{\mathrm{c}} /$ VOT than $/ \mathrm{d} /$; FP produced shorter $/ \mathrm{d}^{\varsigma} / \mathrm{VOT}$ than $/ \mathrm{d} /$. On the other hand, PWS produced shorter $/ \mathrm{t} /$ and $/ \mathrm{t}^{\varsigma} / \mathrm{VOT}$ than FP; their $/ \mathrm{t} / \mathrm{VOT}$ duration was as long as $\mathrm{FP} / \mathrm{t}^{\varsigma} /$ VOT duration. As for F2, FP had $/ \mathrm{t}^{\varsigma} /$ and $/ \mathrm{d}^{\varsigma} / \mathrm{F} 2$ significantly lower than $/ \mathrm{t} /$ and $/ \mathrm{d} / \mathrm{F} 2$. PWS lowered $/ \mathrm{t}^{\varsigma} / \mathrm{F} 2$ but kept $/ \mathrm{d}^{\varsigma} / \mathrm{F} 2$ even higher than its $/ \mathrm{d} / \mathrm{F} 2$ counterpart. FP $/ \mathrm{t}^{\varsigma} / \mathrm{F} 2$ was lower than PWS $/ t^{\natural} / F 2$. This indicates that PWS have less tongue root retraction and less emphasis on the target sound.

Results revealing longer VOT of $/ \mathrm{d}^{\varsigma} /$ than $/ \mathrm{d} /$ contradict previous findings in all normative Arabic studies (Khattab, Al-Tamimi, \& Heselwood, 2006; Komshian et al., 1977). They are in line with English-speaking stuttering studies that report longer VOT durations for PWS than for FPs. PWS have slower motor movements and, accordingly, longer VOT (Hillman \& Gilbert, 1977; Zimmermann, 1980). This slower motor movement is indicative of the neuromotor process dysfuction PWS have (Ludlow \& Loucks, 2003).

Language acquisition studies report that lead/lag VOT dichotomy that Arabic follows is aerodynamically and articulatorily very difficult to acquire and maintain (Kakadelis, 2018). In different languages, lead stops are acquired after short lag stops and around the age of 5;0 (Gandour, Petty, Dardarananda, Dechongkit, \& Mukongeon, 1986; Pan, 1994; Davis, 1995; Kong, 
Beckman, \& Edwards, 2012). Cognitive studies focusing on the categorical perception of VOT as an acoustic cue that discriminates voiceless from voiced plosives report slower processing speeds for PWS during categorical perception and difficulty in accessing phonemic representations in a timely manner (Bakhtiar, Zhang, \& Ki, 2019).

In the current study, the lead/lag VOT dichotomy, as a fine-grained acoustic feature, is difficult for PWS to produce FP-like. Difficulty increases as speakers move from the plain consonant to the emphatic counterpart. Speakers need to coordinate laryngeal vibration timing, oral release timing, laryngeal muscles abduction and adduction, and primary and secondary supralaryngeal configurations (Ward, 2017). The plosives produced in the current study are the emphatic ones that need complex articulatory movements and rapidly shifting configurations (Odisho, 1973) with precise coordination between aerodynamic activity, laryngeal muscle control and rapid supralaryngeal configuration change. Difficulty in maintaining the complex aerodynamicarticulatory activities with the high cognitive-linguistic load (Howell, Anderson, \& Lucero, 2010) required by PWS to internally process and articulatorily maintain plain/emphatic plosives acoustic boundaries results in irregular execution of VOT.

VOT as a subtle fine-grained acoustic cue within a long lead/short lag language like Arabic markedly differentiates between PWS and FP and creates disruption to speech fluency. PWS slowdown of lead emphatics is due to a number of factors: the cognitive load lead VOT creates, the articulatory complexity word-initial emphatic consonants entail (Ward, 2017) and the slower processing speeds that PWS have during categorical perception of VOT (Bakhtiar et al., 2019) .Accordingly, PWS produce /d/ and /d $/$ lead VOT with durations longer than those of FP. As the cognitive load increases with speakers moving from plain to emphatic plosives, PWS produce longer VOT for emphatic than plain plosives. In Arabic studies, and in data produced by FP in the 
current study, the plain plosives have longer VOT than the emphatic counterparts. With stuttering, lead VOT is realized differently. This lengthened lead VOT duration is not witnessed in the short lag of $/ \mathrm{t} /$ and $/ \mathrm{t}^{\mathrm{f}} /$.

As reported in developmental studies, children acquire short lag stops early; they are less difficult to produce than lead stops (Kewley-Port \& Preston, 1974; Bortolini, Zmarich, Fior, \& Bonifacio, 1995). Short lag production requires minimum precise temporal oral and laryngeal occlusion (Kong, Beckman, \&Edwards 2012). Compared to long lead VOT, short lag VOT is achieved with or without active glottal involvement during the oral configuration (Kong, Beckman, \& Edwards, 2011). The small amount of aspiration accompanying short lag VOT is not enough to perceptually categorize it as being aspirated (Abramson \& Whalen, 2018). This small amount of plain /t/ vs. emphatic $/ t^{\natural} /$ VOT is perceptually encoded as more similar to each other and having simultaneous onsets (Toscano, McMurray, Dennhardt, \& Luck, 2010; Jusczyk, Pisoni, Walley, \& Murray, 1980). Due to these factors, minimum temporal precision, lack of production complexity, the perception of the two sounds as having simultaneous onsets with no cognitive load associated with the short lag unaspirated plosives, PWS produce $/ \mathrm{t} /$ and $/ \mathrm{t}^{\varsigma} /$ VOT with shorter values than those of FP.

As for F2 lowering, PWS produce / $\mathrm{d}^{\varsigma} /$ without tongue root retraction and F2 lowering, consequently. Within the context of phonetic transition defect (Wingate, 1969), the lack of F2 lowering indicates the secondary articulation, tongue root retraction, of the emphatic sound is not achieved. Klich \& May's (1982) study on the temporal and spectral features of stuttered tokens show that PWS produce vowel with more temporally and spatially restricted articulation adjustments. Other Studies (Howell \& Vause, 1986; Yaruss \& Conture, 1993; Dehqan, et al, 2016) report higher initial F2 transition slopes, absent or atypical F2 transitions. Results confirm that the 
coarticulation process of PWS differs from that of FP due to the phonetic transition deficit of articulators moving on from one sound to another in a timely manner. The articulatory deficit with the restricted articulation adjustments PWS have result in less emphatic $/ \mathrm{t}^{\mathrm{f}} /$ and deemphasized $/ \mathrm{d}^{\varsigma} /$. The reduced emphasis indicates that PWS do not appropriately retract tongue root. This being the case, less articulatory gestures and complexity are manifested.

The overall view of the results showed that, there were significant differences between PWS and FP in their production of $/ \mathrm{d}^{\varsigma} /$ and $/ \mathrm{t}^{\mathrm{f}} / \mathrm{VOT}$ and $\mathrm{F} 2$. Their atypical VOT durations and $\mathrm{F} 2$ values are in line with what is generally found in English-speaking stuttering studies. They behave differently from FP based on whether the sound is articulatorily and cognitively complex and loaded or not.

\section{Conclusion}

The current study is the first Arabic study that examines the role of complex emphatic sounds on the excitation of stuttering. VOT and F2 were measured in four monosyllabic plain-emphatic words. PWS were found to produce lead and lag VOT different from FP typical productions. F2 onset of the vowel following the emphatic sound and reflecting the amount of emphasis was also affected. Findings go on line with the atypicality of PWS VOT and F2 reported in English-speaking stuttering studies. This atypicality is realized differently in Arabic depending on the articulatory complexity and cognitive load of the sound.

\section{Disclosure of interest}

Author wishes to confirm that there are no known conflicts of interest associated with this publication and there has been no financial support for this.

IRB Approval: Research ethically approved by the IRB committee Ref. Number: 27/131/2020 


\section{References}

Abdalla, F., Robb, M. P. \& Al-Shatti, T. (2009). Stuttering and lexical category in adult Arabic speakers. Clinical Linguistics \& Phonetics, 24(1), 70-81.

Abramson, A. S. \& Whalen, D. H. (2017). Voice onset time (VOT) at 50: Theoretical and practical issues in measuring voicing distinctions. Journal of Phonetics, 63, 75-86.

Al-Ani, S. H. (1970). Arabic phonology: An acoustical and physiological investigation. The Hague: Mouton.

Al-Tamimi, F., Alzoubi, F. \& Tarawnah R. (2009). A videofluoroscopic study of the emphatic consonants in Jordanian Arabic. Folia Phoniatrica et Logopaedica, 61(4), 247-253.

Al-Tamimi, F. \& Heselwood, B. (2011). Nasoendoscopic, Video-fluoroscopic and Acoustic Study of Plain and Emphatic Coronals in Jordanian Arabic. In: B. Heselwood \& Z. M. Hassan (Eds.), Instrumental Studies in Arabic Phonetics. Current Issues in Linguistic Theory. Amsterdam \& Philadelphia: John Benjamins, 319, 165-191.

Al-Tamimi, F., Khamaiseh, Z. \& Howell, P. (2013). Phonetic complexity and stuttering in Arabic. Clinical Linguistics and Phonetics, 27(12), 874-887.

Al-Tamimi, F., Tarawneh, R. \& Howell, P. (Submitted). Development of voice onset time in Arabic.

Amayreh, M. (2003). Completion of the consonant inventory of Arabic. Journal of Speech, Language, and Hearing Research, 46, 517-529.

Arenas, R. M., Zebrowski, P. M. \& Moon, J. B. (2012). Phonetically governed voicing onset and offset in preschool children who stutter. Journal of Fluency Disorders, 37(3), 179-187. 
Aslin, R. N., Pisoni, D. B., Hennessy, B. L. \& Perey, A. J. (1981). Discrimination of voice onset time by human infants: New findings and implications for the effects of early experience. Child Development, 52, 1135-1145.

Bakhtiar, M., Zhang, C., \& Sze Ki, S. (2019). Impaired processing speed in categorical perception: Speech perception of children who stutter. PloS one, 14(4), e0216124. https://doi.org/10.1371/journal.pone.0216124

Bauerly, K.R. (2018). The effects of emotion on second formant frequency fluctuations in adults who stutter. Folia Phoniatrica et Logopaedica, 70(1), 13-23.

Bauerly, K.R. \& Paxton, J. (2017). Effects of emotion on the acoustic parameters in adults who stutter: An exploratory study. Journal of Fluency Disorders, 54, 35-49. https://doi.org/10.1016/j.jfludis.2017.09.006.

Bauerly, K. R., Jones, R. M. \& Miller, C. (2019). Effects of social stress on automatic, behavioral, and acoustic parameters in adults who stutter. Journal of Speech, Language and Hearing. 62(7), 2185-2202

Borden, G. J., Baer, T. B. \& Kenney, M. K. (1985). Onset of voicing in stuttered and fluent utterances. Journal of Speech and Hearing Research, 28, 363-372.

Bortolini, U., Zmarich, C., Fior, R., \& Bonifacio, S. (1995). Word-initial voicing in the productions of stops in normal and preterm Italian infants. International journal of pediatric otorhinolaryngology, 31(2-3), 191-206. https://doi.org/10.1016/0165-5876(94)01091-b 
Brown, S. F. (1937). The influence of grammatical function on the incidence of stuttering. Journal of Speech Disorders, 2. 207-215.

Brown, S. F. (1938a). A further study of stuttering in relation to various speech sounds. Quarterly Journal of Speech, 24, 390-397.

Brown, S. F. (1938b). Stuttering with relation to word accent and word position. Journal of Abnormal and Social Psychology, 33, 112-120.

Brown, S. F. \& Moren, A. (1942). The frequency of stuttering in relation to word length during oral reading. Journal of Speech Disorders, 7, 153-159.

Brown, S. F. (1945). The loci of stutterings in the speech sequence. Journal of Speech Disorders, 10, 181-192.

Buhr, A. P. \& Zebrowski, P. M. (2009). Sentence position and syntactic complexity of stuttering in early childhood: A longitudinal study. Journal of Fluency Disorders, 34, 155-172.

Caruso, A. J., Abbs, J. H. \& Gracco, V. L. (1988). Kinematic analysis of multiple movement coordination during speech in stutterers. Brain: A Journal of Neurology, 111, 439-456.

Chang, S., Horwitz, B., Ostuni, J., Reynolds, R. \& Ludlow, C. L. (2011) Evidence of left inferior frontal-premotor structural and functional connectivity deficits in adults who stutter. Cerebral Cortex, 21(11), 2507-2518.

Cho, T. \& Ladefoged, P. (1999). Variation and universal in VOT: evidence from 18 languages. Journal of Phonetics, 27, 207-227.

Conture, E. G., Schwartz, H. D. \& Brewer, D. (1985). Laryngeal behaviour during stuttering: A further study. Journal of Speech and Hearing Research, 28, 233-40. 
Cook, C. (2008). Clinimetrics corner: use of effect sizes in describing data. The Journal of Manual \& Manipulative Therapy, 16, 54-7.

Cooper, M. H. \& Allen, G.D. (1977). Timing control accuracy in normal speakers and stutterers. Journal of Speech and Hearing Research, 20, 55-71.

Davis, K. (1995). Phonetic and phonological contrasts in the acquisition of voicing: voice onset time production in Hindi and English. Journal of Child language, 22(2), 275-305.

Dehqan, A., Yadegari, F., Blomgren, M., \& Scherer, R. C. (2016). Formant transitions in the fluent speech of Farsi-speaking people who stutter. Journal of Fluency Disorders, 48, 1-15.

De Nil, L. F. (1999). Stuttering: A neurophysiological perspective. In N. Bernstein Ratner \& C. Healey (Eds.), Stuttering research and practice: Bridging the gap, Mahwah, NJ: Erlbaum, $85-102$.

Deuchar, M. \& Clark, A. (1996). Early bilingual acquisition of the voicing contrast in English and Spanish, Journal of Phonetics, 2(3), 351-365.

Didirková, I. \& Hirsch, F. (2019). A two-case study of coarticulation in stuttered speech. An articulatory approach. Clinical Linguistics \& Phonetics. $34 . \quad 517-535$. 10.1080/02699206.2019.1660913.

Frisch, S. A., Maxfield, N., \& Belmont, A. (2016). Anticipatory coarticulation and stability of speech in typically fluent speakers and people who stutter. Clinical linguistics \& phonetics, 30(3-5), 277-291. https://doi.org/10.3109/02699206.2015.1137632 
Gandour, J., Petty, S. H., Dardarananda, R., Dechongkit, S. \& Mukngoen, S. (1986). The acquisition of the voicing contrast in Thai: A study of Voice Onset Time in word-initial stop consonants. Journal of Child Language, 13, 561-572.

Hawkins, D. B., Walden, B. E., Montgomery, A. \& Prosek, R. A. (1987). Description and validation of an LDL procedure designed to select SSPL90. Ear and Hearing, 8, 162-169.

Hay, J. (2005) How auditory discontinuities and linguistic experience affect the perception of speech and non-speech in English- and Spanish-speaking listeners. PhD thesis (University of Texas at Austin, Austin).

Healey, E. C. \& Gutkin, B. (1984). Analysis of stutterers' voice onset times and fundamental frequency contours during fluency, Journal of Speech and Hearing Research, 27, $219-225$.

Hillman, R. E. \& Gilbert, H. R. (1977) Voice onset times for voiceless stop consonants in the fluent reading of stutterers and nonstutterers, Journal of the Acoustical Society of' America, 61, 610-611.

Hirose, H., Yoshioka, H. \& Niimi, S. (1978). A cross language study of laryngeal adjustment in consonant production. Annual Bulletin, Research Institute of Logopedics and Phoniatrics. 12, 61-71.

Howell, P., \& Harvey, N. (1983). Perceptual equivalence and motor equivalence in speech. In B. Butterworth (Ed.), Language Production, Vol. 2, 203-224. Academic Press.

Howell, P. \& Vause, L. (1986). Acoustic analysis and perception of vowels in stuttered speech. Journal of the Acoustical Society of America, 79, 1571-1579. 
Howell, P., Williams, M. \& Vause, L. (1987). Acoustic analysis of repetitions in stutterer's speech. In H. F. M. Peters \& W. Hulstijn (Eds.) Speech motor dynamics in stuttering. Wein. Springer Verlag, NY, 371-380.

Howell, P. \& Williams, M. (1992). Acoustic analysis and perception of vowels in children's and teenagers' stuttered speech. Journal of the Acoustical Society of America, 91, $1697-1706$.

Howell, P. (1996). Producing and perceiving speech. In D Green et al. (Eds.). Cognitive Science. Pp.120-147. Oxford: Blackwell.

Howell, P., Au-Yeung, J. \& Sackin, S. (2000). Exchange of stuttering from function words to content words with age. Journal of Speech, Language and Hearing Research, 42, 345-354.

Howell, P., Anderson, A. \& Lucero, J. C. (2010). Speech motor timing and fluency, In B. Maasen \& P. van Lieshout (Eds.) Speech Motor Control - New Developments in Basic and Applied Research, Oxford University Press, 215-225.

Howell, P., Au-Yeung, J., Yaruss, J. S. \& Eldridge, K. (2006). Phonetic difficulty and stuttering in English. Clinical Linguistics and Phonetics, 20, 703-716.

Howell, P. \& Rusbridge, S. (2011). The speech and language characteristics of English monolingual speakers who stutter at different ages. In P. Howell \& J. van Borsel (Eds). Multilingual Aspects of Fluency Disorders. In series: Communication Disorders across Languages. Multilingual Matters, Bristol, England (Müller, N. \& Ball, M. series Eds.), 93-138.

Jakielski, K. J. (1998). Motor organization in the acquisition of consonant clusters. $\mathrm{PhD}$ thesis, University of Texas at Austin: Ann Arbor Michigan, UMI Dissertation services. 
Johnson, W. \& Brown, S. F. (1935). Stuttering in relation to various speech sounds. The Quarterly Journal of Speech, 21.481-496.

Jongman, A., Herd, W. \& Al-Masri, M. (2007). Acoustic correlates of emphasis in Arabic. International Congress of Phonetics Sciences, XVI, 913-916. Kansas Working Papers in Linguistics, Vol. 32 (2011), 20-47.

Jusczyk, P., Pisoni, D., Walley, A. \& Murray, J. (1980). Discrimination of relative onset time of two-component tones by infants. Journal of the Acoustical Society of America, 67, 262270.

Kakadelis, S. M. (2018). Phonetic Properties of Oral Stops in Three Languages with No Voicing Distinction, CUNY Academic Works.

Kewley-Port, D. \& Preston M. S. (1974). Early apical stop production: a voice onset time analysis. Journal of Phonetics, 2, 194-210.

Khattab, G. 2000. VOT Production in English and Arabic bilingual and monolingual children. Leeds working papers in Linguistics \& Phonetics. 8, 95-122.

Khattab, G., Al-Tamimi, F. \& Heselwood, B. (2006). Acoustic and auditory differences in the /t/-/t/ opposition in male and female speakers of Jordanian Arabic, In S. Boudelaa (Ed.), Perspectives on Arabic Linguistics XVI: Papers from the sixteenth annual symposium on Arabic linguistics. John Benjamins, 131-160.

Kleinow, J. \& Smith, A. (2000). Influences of length and syntactic complexity on the speech motor stability of the fluent speech of adults who stutter. Journal of Speech, Language and Hearing Research, 43, 548-59. 
Klich, R. \& May, G. (1982). Spectrographic study of vowels in stutterers' fluent speech. Journal of Speech and Hearing Research, 25, 364-370.

Kong, E. J. (2009). The development of phonation-type contrasts in plosives: Crosslinguistic perspectives. $\mathrm{PhD}$ thesis. The Ohio State University.

Kong, E. J, Beckman, M.E. \& Edwards, J. (2011). Why are Korean tense stops acquired so early: The role of acoustic properties, Journal of Phonetics, 39, 196-211.

Kong, E. J., Beckman, M. E. \& Edwards, J. (2012). Voice onset time is necessary but not always sufficient to describe acquisition of voiced stops: The cases of Greek and Japanese Journal of phonetics, 40(6), 725-744.

Llewellyn, D. A. (1994). Voice Onset Time as a Function of Word Stress in Speech Development: M. S. Thesis. Texas Tech University, Health Sciences Center.

Loucks, T. M. J. \& De Nil, L. F. (2006). Oral kinesthetic deficit in adults who stutter: A target-accuracy study. Journal of Motor Behavior, 38(3):238-247.

Ludlow, C. L. \& Loucks, T. (2003). Stuttering: A dynamic motor control disorder. Journal of Fluency Disorders, 28, 273-295.

MacNeilage, P. F. \& Davis, B. L. (2000). Deriving speech from nonspeech: A view from ontogeny. Phonetica, 57, 284-296.

MacPherson, M. K. \& Smith, A. (2013). Influences of sentence length and syntactic complexity on the speech motor control of children who stutter. Journal of Speech, Language, and Hearing Research, 56, 89-102. 
Marshall, C. (2005). The impact of word-end phonology and morphology on stuttering. Stammering Research, 1, 375-391.

Max, L. \& Gracco, V. L. (2005). Coordination of oral and laryngeal movements in the perceptually fluent speech of adults who stutter. Journal of Speech Language \& Hearing Research, 48(3):524-42.

McClean, M. D. (2004). Orofacial movements associated with fluent speech in persons who stutter. Journal of Speech, Language, and Hearing Research, 47, 294-303.

McClean, M. D., Kroll, R. M. \& Loftus, N. S. (1990). Kinematic analysis of lip closure in stutterers' fluent speech. Journal of Speech and Hearing Research, 33, 755-760.

Odisho, E. Y. (1973). The role of the rear section of the vocal tract in Baghdadi Arabic. Unpublished M. Phil thesis, Leeds University.

Pan H. (1994). The voicing contrasts of Taiwanese (Amoy) initial stops: data from adults and children. $\mathrm{PhD}$ thesis. Ohio State University;

Rezaei-Aghbash, N., Whiteside, S. P., James, S. \& Cudd, P. A. (2000). Cross-language analysis of stuttered speech. Journal of Fluency Disorders, 25(3):248-249.

Riley, G. D. (1994). Stuttering severity instrument for children and adults (SSI-3) (3rd Ed.). Pro-Ed, Inc; Austin, TX.

Robb, M. \& Blomgren, M. (1997). Analysis of F2 transitions in the speech of stutterers and non-stutterers. Journal of Fluency Disorders, 22(1), 1-16.

Robb, M., Gilbert, H. \& Lerman, J. (2005). Influence of gender and environmental setting on VOT. Folia Phoniatrica et Logopaedica, 57, 125-133. 
Roud, A. (2011). Anxiety level in stuttering children. Unpublished PhD thesis, Arab Amman University, Jordan.

Rosen, S. \& Howell, P. (1987). Is there a natural sensitivity at $20 \mathrm{~ms}$ in relative tone-onset-time continua? A reanalysis of Hirsh's (1959) data. In The Psychophysics of Speech Perception. M.E.H. Schouten (Ed.). Dordrecht: Martinus Nijhoff, 199-209.

Shapiro, A. (1980). An electromyographic analysis of the fluent and dysfluent utterance of several types of stutterers. Journal of fluency Disorders, 5, 203-231.

Smith, A. (1999). Stuttering: A unified approach to a multifactorial, dynamic disorder. In N. Bernstein Ratner \& E. C. Healey (Eds.), Stuttering Research and Practice: Bridging the Gap. Mahwah, NJ: Lawrence Erlbaum Associates, Inc., 27-44.

Smith, A., Sadagopan, N., Walsh, B., \& Weber-Fox, C. (2010). Increasing phonological complexity reveals heightened instability in inter-articulatory coordination in adults who stutter. Journal of fluency disorders, 35(1), 1-18. https://doi.org/10.1016/j.jfludis.2009.12.001

Smith, A., Goffman, L., Sasisekaran, J. \& Weber-Fox, C. (2012). Language and motor abilities of preschool children who stutter: Evidence from behavioral and kinematic indices of nonword repetition performance. Journal of Fluency Disorders, 37, 344-58.

Sussman, H. M., Byrd, C. T., \& Guitar, B. (2011). The integrity of anticipatory coarticulation in fluent and non-fluent tokens of adults who stutter. Clinical linguistics \& phonetics, 25(3), 169-186. https://doi.org/10.3109/02699206.2010.517896 
Throneburg, R. N., Yairi, E. \& Paden, E. P. (1994). Relation between phonologic difficulty and the occurrence of disfluencies in the early stage of stuttering. Journal of Speech and Hearing Research, 37, 504-509.

Toscano, J. C., McMurray, B., Dennhardt, J. \& Luck, S. J. (2010). Continuous perception and graded categorization: Electrophysiological evidence for a linear relationship between the acoustic signal and perceptual encoding of speech, Psychological Science, 21(10):1532-40.

Usler, E., Smith, A. \& Weber, C. (2017). A lag in speech motor coordination during sentence production is associated with stuttering persistence in young children. Journal of Speech, Language, \& Hearing Sciences, 60, 51-61. Doi: 10.1044/2016_JSLHR-D-15-0367.

Van Riper, C. (1982). The Nature of Stuttering. (2nd edition) New Jersey: Prentice-Hall. Van Riper, C. (1990). Final thought about stuttering. Journal of Fluency Disorders, 15, $317-318$.

Viswanath, N. S., \& Rosenfield, D. B. (2000). Preponderance of lead voice onset times in stutterers under varying constraints. Communication Disorders Quarterly, 22(1), 49-55.

Walsh, B., \& Smith, A. (2013). Oral electromyography activation patterns for speech are similar in preschoolers who do and do not stutter. Journal of Speech, Language, and Hearing Research, 56, 1441-1454.

Ward, D. (2017). Stuttering and cluttering: frameworks for understanding and treatment. 2nd edition. CRC Press.

Watson, J. (2007). The Phonology and Morphology of Arabic. Oxford University Press. 
Wingate, M. E. (1969). Stuttering as phonetic transition defect. Journal of Speech and Hearing Disorders, 34, 07-108.

Wingate, M. E. (2002). Foundations of Stuttering. San Diego CA: Academic Press.

Yairi, E. \& Ambrose, N. (2005). Early Childhood Stuttering. Austin, TX: Pro-Ed.

Yaruss, J. S. \& Conture, E. G. (1993). F2 transitions during sound/syllable repetitions of children who stutter and predictions of stuttering chronicity. Journal of Speech, Language, and Hearing Research, 36(5), 883-896.

Yeni-Komshian, G.H., Caramazza, A. \& Preston, M.S. (1977). A study of voicing in Lebanese Arabic. Journal of Phonetics, 5. 35-48.

Zawaydeh, B. (1999). The phonetics and phonology of gutturals in Arabic. PhD. thesis, Bloomington, IN: Indiana University.

Zebrowski, P, Conture, E. \& Cudahy, E. (1985). Acoustic analysis of young stutters' fluency: Preliminary observation. Journal of Fluency Disorders, 10:173-192.

Zeroual, C., Hoole, P., Fuchs, S. \& Esling, J. H. (2007). EMA study of the coronal emphatic and non-emphatic plosive consonants of Moroccan Arabic. Proceedings of the XVIth ICPHS, 397340.

Zimmermann, G. (1980) Stuttering: A disorder of movement. Journal of Speech and Hearing Research, 2S, 122-136. 


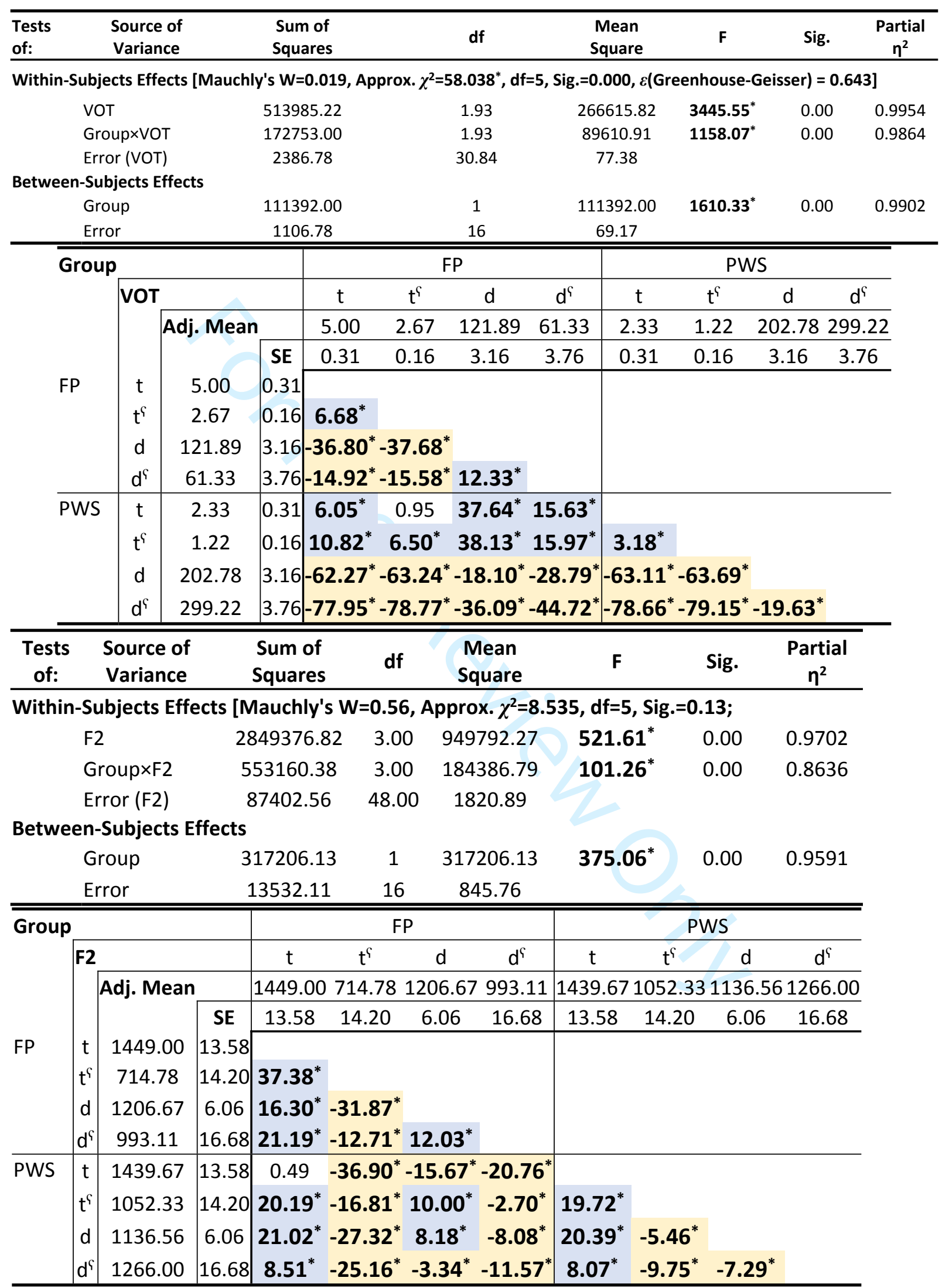

Table 1: VOT and F2 produced by FP and PWS 